\title{
Synthesis, Growth and Material Characterization of Bis L-Alanine Triethanol Amine (BLATEA) Single Crystals Grown by Slow Evaporation Technique
}

\section{T. Vela ${ }^{a}$, P. Selvarajan ${ }^{b}$, T. H. Freeda ${ }^{c}$}

\author{
${ }^{a}$ Department of Physics, The M.D.T. Hindu College, Tirunelveli-627010, Tamilnadu, India. \\ ${ }^{\mathrm{b}}$ Department of Physics, Aditanar College of Arts and Science, Tiruchendur-628216, Tamilnadu, \\ India. \\ ${ }^{c}$ Department of Physics, S.T. Hindu College, Nagercoil-629002, Tamilnadu, India. \\ *Corresponding author: pselvarajanphy@yahoo.co.in
}

\begin{abstract}
Bis L-alanine Triethanol amine (BLATEA) salt was synthesized by solution method and it was subjected to solubility studies. Using the solubility data, the saturated solution of the synthesized salt was prepared and single crystals of Bis L-alanine Triethanol amine (BLATEA) were grown from aqueous solution by slow evaporation technique. X-ray diffraction (XRD) study was carried out to confirm the crystal structure. FTIR study reveals the functional groups of the sample. $U V$-Visible transmittance and absorption spectra were recorded for the sample to analyze the transparency of the grown crystal. Vickers micro hardness values were measured for the sample and from the microhardness study it is observed that BLATEA crystal is a soft material. SHG generation study was carried out to confirm the NLO activity of grown sample and also BLATEA crystal has been analyzed with dielectric measurements
\end{abstract}

Keywords: NLO crystal; Crystal growth; Single crystal; Characterization; XRD; FTIR; microhardness; dielectric constant; activation energy

\section{INTRODUCTION}

Many efforts are being made recently to combine amino acids with different organic and inorganic acids and salts to synthesize outstanding Nonlinear Optical (NLO) materials and these materials are of great interest because of their significant impact on LASER technology, optical 
communication and optical data storage and optical data processing etc [1]. The overwhelming success of molecular engineering in controlling NLO properties in the last decade has promoted better initiatives in crystal engineering [2]. Organic molecular crystals have received a great deal of attention in recent years due to their extremely large optical non-linearities compared with most of the inorganic crystals [3]. The organic materials play in an important role in second harmonic generation (SHG) [4]. L-alanine [5] is an organic $\alpha$-amino acid with the chemical formula $\mathrm{CH}_{3} \mathrm{CHNH}_{2} \mathrm{COOH}$. It is classified as non-polar amino acid and was first crystallized by Bernal [6] and later by Simpson [7] and Destro et.al [8] and it is the simplest acentric crystal with second harmonic generation efficiency of about 0.3 times that of the well known KDP [911]. If L-alanine is mixed with different organic and inorganic acids and salts [12] to form novel materials, it is expected to get improved NLO properties. Some complexes of $\mathrm{L}$-alanine have been recently crystallized and various studies have been investigated by many researches [1314]. Triethanol amine is an organic material with the molecular formula $\mathrm{C}_{6} \mathrm{H}_{15} \mathrm{NO}_{3}$ and it is a liquid with an ammonia aroma. It is soluble in chloroform, water and alcohol and boiling at $335{ }^{\circ} \mathrm{C}$. It is used in dry cleaning soaps, cosmetics, textile processing and as corrosion inhibitor. In this work, L-alanine and triethanol amine were used to form a new NLO crystal from aqueous solution. Crystal growth from solution is an important process that is used in many applications from laboratories to industrial scale [15]. The aim of this work is to grow single crystals of BLATEA by slow evaporation growth technique and to characterize the grown crystal by various studies such as structural, optical, mechanical and dielectric studies.

\section{EXPERIMENTAL TECHNIQUES}

\subsection{Synthesis}

The title compound BLATEA was synthesized by taking the chemicals such as AR grade Lalanine and triethanol amine in the molar ratio 2:1. The calculated amounts of the precursor chemicals were dissolved in de-ionized water and stirred well using a magnetic stirrer for about 2 hours. The solution was heated until the synthesized salt of BLATEA was obtained. During the synthesis, temperature of the solution was maintained at $50{ }^{0} \mathrm{C}$ in order to avoid the decomposition of the sample. The purity of the synthesized salt was improved by repeated recrystallization.

\subsection{Solubility Study}

The solubility of BLATEA in de-ionized water was determined as a function of temperature in the range of 30 to $50{ }^{\circ} \mathrm{C}$. The beaker containing the solution was initially maintained at $30{ }^{\circ} \mathrm{C}$ and continuously stirred using a magnetic stirrer. The amount of BLATEA required to saturate the solution at this temperature was estimated by gravimetrical method [16]. The solubility curve for BLATEA sample is shown in Figure 1. From the results, it is observed that solubility 
increases with temperature for the sample and the sample has positive temperature coefficient of solubility. Solubility data is necessary to prepare the saturated solution of the sample at a particular temperature.

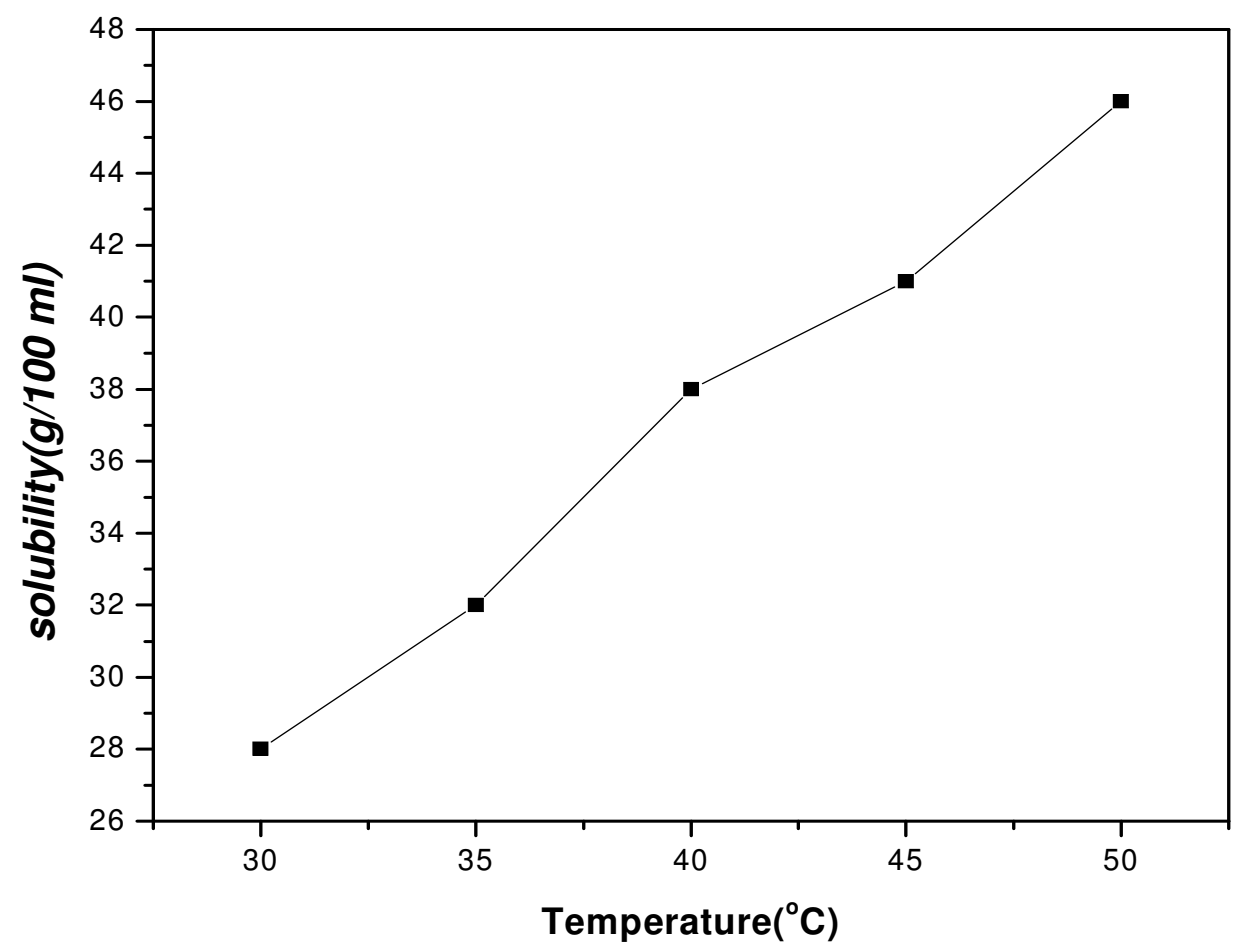

Fig. 1: Variation of solubility with temperature for BLATEA

\subsection{Growth of BLATEA Crystals}

Solution method with slow evaporation technique was adopted to grow the single crystals of the synthesized salt of BLATEA. In accordance with the solubility data, the saturated solution was prepared and it was constantly stirred for about 2 hours using a magnetic stirrer. Then it was filtered using a 4 micro Whatmann filter paper and the filtered solution was kept in a borosil beaker covered with a porous paper. The grown crystal was harvested after a period of 20 days and it is displayed in the photograph (Fig.2). 


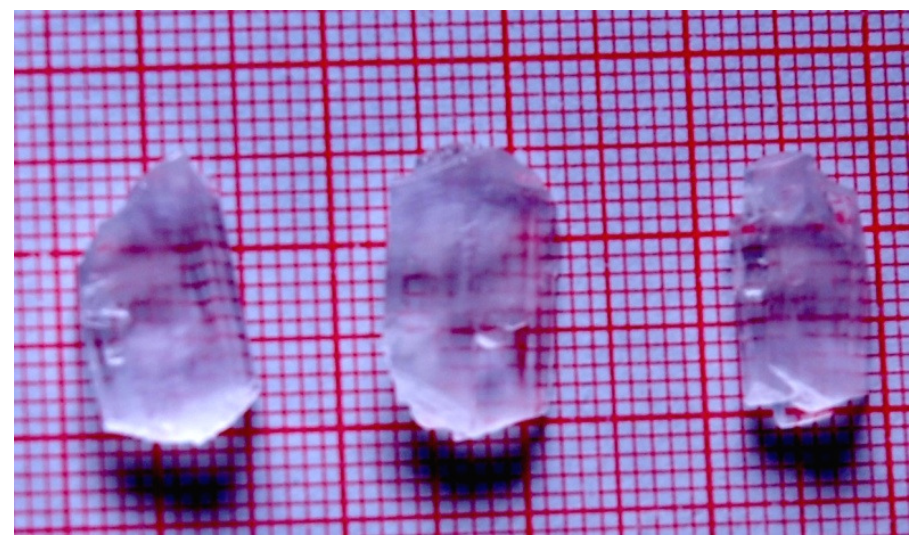

Fig. 2: The grown BLATEA single crystals

\subsection{Characterization Methods}

Single crystal XRD data for BLATEA crystal was obtained by employing Bruker-Nonious MACH3/CAD4 single X-ray diffractometer with $\mathrm{MoK}_{\alpha}$ radiation $(\lambda=0.71073 \AA$ ). To identify the reflection planes, powder X-ray diffraction pattern of the powdered sample was obtained using a powder X-ray diffractometer (PANalytical Model, Nickel filtered $\mathrm{Cu} \mathrm{K} \mathrm{K}_{\alpha}$ radiations with $\lambda=1.54056 \AA$ at $35 \mathrm{kV}, 10 \mathrm{~mA}$ ). The sample was scanned over the required range for $2 \Theta$ values $\left(10-70^{\circ}\right)$. The FTIR spectrum of the sample was recorded using a Shimadzu $8400 \mathrm{~S}$ spectrometer by the $\mathrm{KBr}$ pellet technique in the range $400-4500 \mathrm{~cm}^{-1}$. The optical spectra of BLATEA crystal have been recorded in the region 190-1100 nm using a Perkin Elmer (Model:Lambda 35) UV-vis-NIR spectrophotometer. Microhardness test was carried out using a Leitz Weitzler hardness tester fitted with a diamond indenter. Smooth, flat face (001) of the grown BLATEA crystal was polished and subjected to the hardness study. Indentations were made for various loads from $25 \mathrm{~g}$ to $100 \mathrm{~g}$. Several trials of indentation were carried out and the average diagonal lengths were measured for an indentation time of 10 seconds. The Vickers microhardness number was calculated using the relation $\mathrm{Hv}=1.8544 \mathrm{P} / \mathrm{d}^{2} \mathrm{~kg} / \mathrm{mm}^{2}$ where $\mathrm{P}$ is the applied load and $\mathrm{d}$ is the diagonal length of the indentation [17,18]. The Second Harmonic Generation (SHG) efficiency for the sample was measured by Kurtz-Perry powder technique [19]. The BLATEA crystal was powdered with uniform particle size using a ball mill and it was packed densely between two transparent glass slides. An Nd:YAG laser was used as a light source. This laser device can be operated in two different-modes. In the single-shot mode, the laser emits an $8 \mathrm{~ns}$ pulse. While in the multi-shot mode, the laser produces a continuous train of 8 ns pulse at a repetition rate of $10 \mathrm{~Hz}$. In the present study, a multi-shot mode of 8 ns laser pulse with a spot radius of $1 \mathrm{~mm}$ was used. The experimental set-up for measuring SHG efficiency is shown in Figure 3. The fundamental laser beam of $1064 \mathrm{~nm}$ wavelength was made to fall normally on the sample cell(S). The power of the incident beam was measured using a power meter. The filter F1 removes the 1064 nm light and the filter F2 is a BG-38 filter, which also 
removes the residual $1064 \mathrm{~nm}$ light. F3 is an interference filter with bandwidth of $4 \mathrm{~nm}$ and central wavelength $532 \mathrm{~nm}$. The green light was detected by a photomultiplier tube (PMT) and displayed on a Cathode Ray Oscilloscope (CRO). KDP crystal was powdered into identical size as BLATEA crystal and it was used as reference material in the SHG measurement.

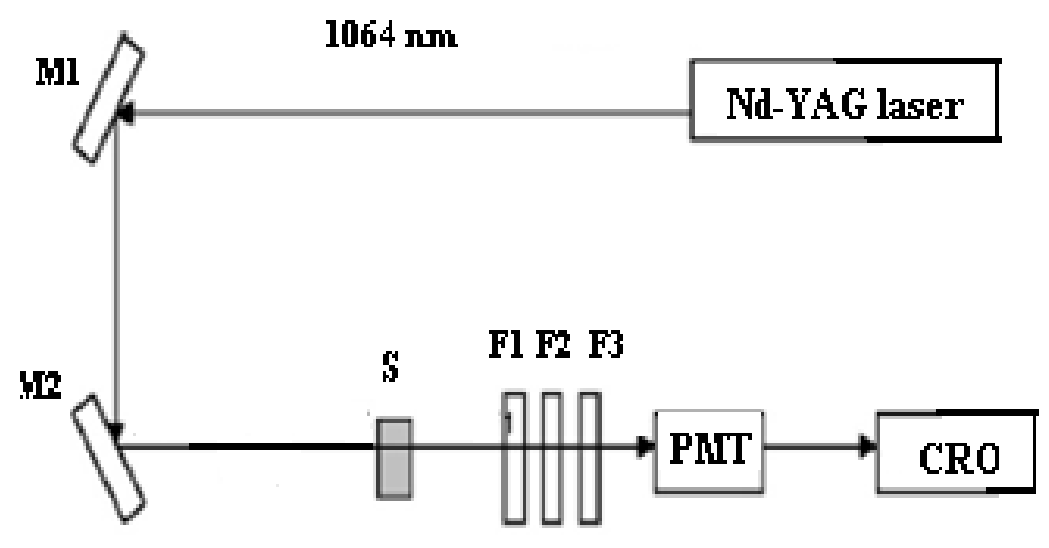

Fig. 3: Experimental setup for measuring relative SHG efficiency

\section{RESULTS AND DISCUSSION}

\subsection{Structural Characterization}

Powder XRD method is useful for confirming the identity of a crystalline material and determining the phase purity. Bis L-alanine triethanol amine (BLATEA) crystal was ground into powder and it is subjected to powder X-ray diffraction studies. The powder XRD pattern of the sample is shown in Figure 4. The well-defined peaks at specific $2 \Theta$ values show high crystallinity of the grown crystals. All the reflections of powder XRD patterns of this work were indexed using the INDEXING and TREOR software packages. The lattice parameters obtained from the indexed XRD patterns using UNITCELL software package. Table 1 provides the lattice parameters of BLATEA crystal from single crystal XRD study and it observed from the data that the lattice parameters of BLATEA crystal obtained from powder XRD study are comparable with those obtained from single crystal XRD study. From XRD studies, it is noticed that grown BLATEA crystal crystallizes in orthorhombic structure. 


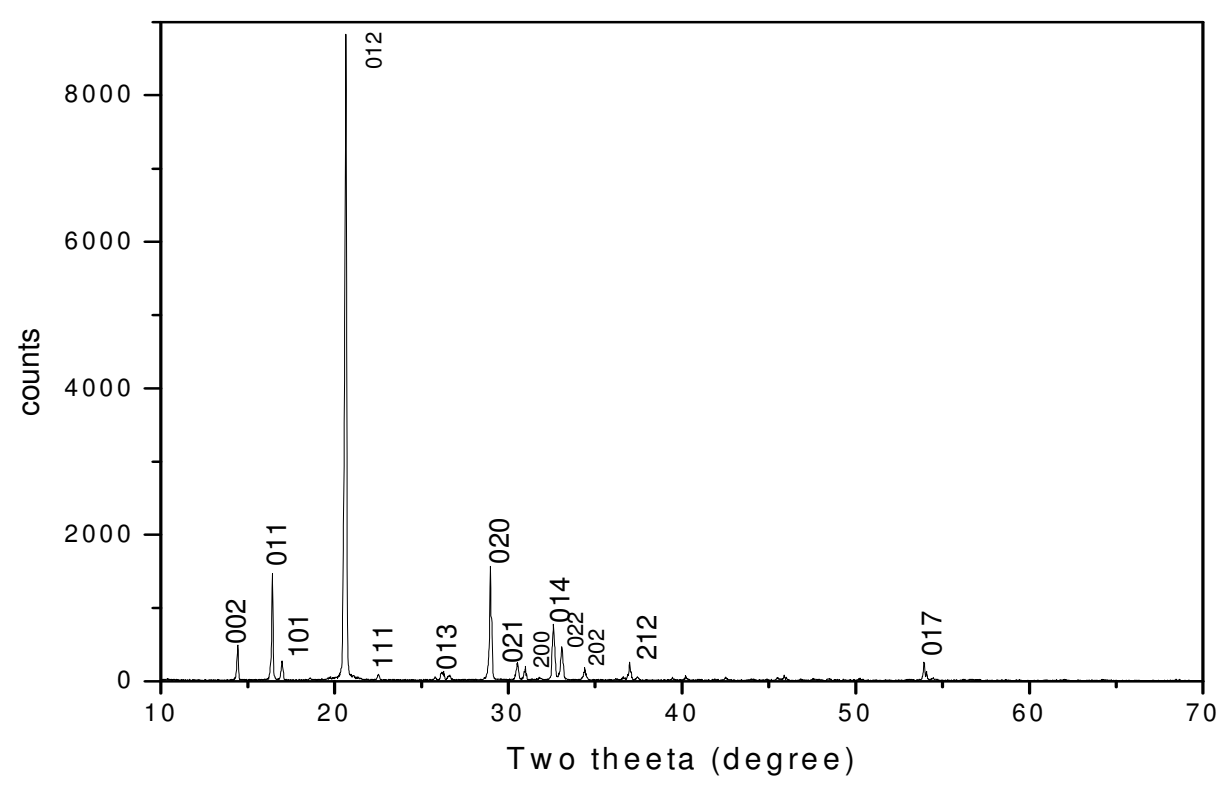

Fig. 4: Powder XRD pattern for powdered sample of BLATEA crystal

Table 1: Unit cell parameters for BLATEA crystal

\begin{tabular}{|l|c|}
\hline Sample & Cell parameters \\
\hline Bis L-alanine Triethanol & $\mathrm{a}=5.843(4) \AA$ \\
amine (BLATEA) & $\mathrm{b}=6.125(3) \AA$ \\
& $\mathrm{c}=12.114(2) \AA$ \\
& $\alpha=\beta=\gamma=90^{\circ}$ \\
\hline
\end{tabular}

\subsection{Optical Characterization}

The FTIR spectrum of the grown BLATEA crystal was recorded in the $\mathrm{KBr}$ phase in the frequency region $450-4500 \mathrm{~cm}^{-1}$ using Perkin Elmer spectrometer and is shown in Figure 5. The assignments for the absorption peaks / bands are provided in accordance with the data reported in the literature [20]. The $\mathrm{CH}_{2}$ scissoring, $\mathrm{COO}^{-}$symmetric stretching, $\mathrm{CH}_{3}$ symmetric bending and $\mathrm{O}-\mathrm{H}$ bending vibrations produce peak at $1454 \mathrm{~cm}^{-1}, 1412 \mathrm{~cm}^{-1}, 1360 \mathrm{~cm}^{-1}$ and $1302 \mathrm{~cm}^{-1}$ respectively. $\mathrm{NH}_{2}$ stretching and $\mathrm{NH}_{2}$ scissoring vibrations produce peak at $3408 \mathrm{~cm}^{-1}$ and 1616 $\mathrm{cm}^{-1}$. FTIR spectrum reveals that L-alanine is protonated by the carboxyl group. The observed absorption peaks/bands and the wave number assignments of BLATEA sample are given in Table 2. 


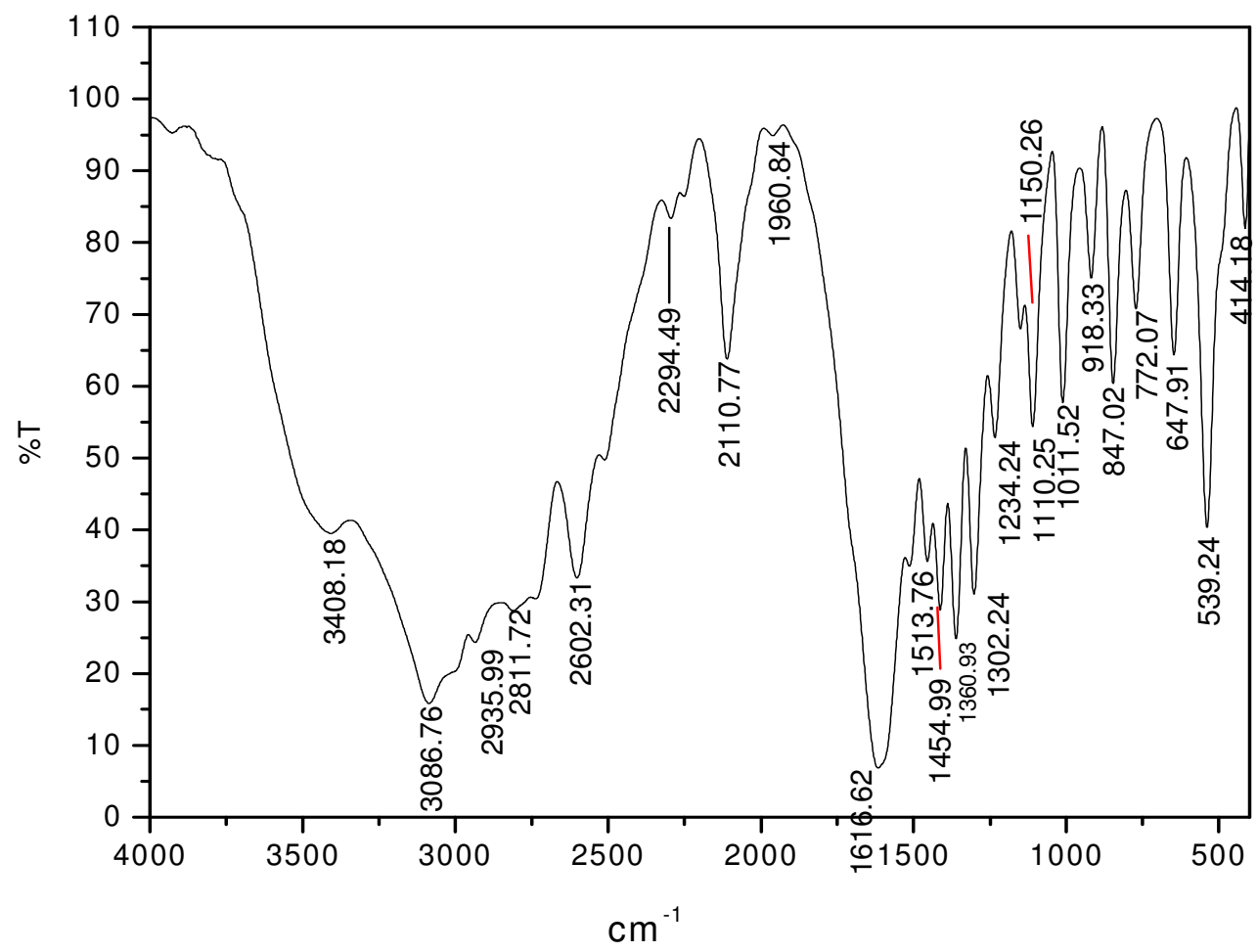

Fig. 5: FTIR spectrum for Bis L-alanine Triethanol amine sample

In order to determine the optical transmission characteristics of the grown crystal, UV-vis-NIR spectrum was recorded using a spectrophotometer. Optically clear single crystal of thickness about $2 \mathrm{~mm}$ was used for this study. UV-visible absorption and transmittance spectra of bis Lalanine triethanol amine crystal in the wave length region 200-1100 nm are shown in Figures 6 and 7. This spectral study may be assisted in understanding electronic structure of the optical band gap of the crystal.

In order to confirm Nonlinear Optical (NLO) property, microcrystalline form of the grown crystal was packed between two transparent glass slides (sample cell). Second-harmonic radiation generated by the randomly oriented micro crystals was focused by a lens and detected by a photomultiplier tube after filtration of the incident or fundamental radiation of $1064 \mathrm{~nm}$. The doubling of frequency was confirmed by the green color of the output radiation whose characteristic wavelength is $532 \mathrm{~nm}$. The relative measured output from the specimen with respect to KDP crystal shows that SHG efficiency of the grown BLATEA crystal is 0.61 times that of KDP. 
Table 2: FTIR spectral assignments for BLATEA crystal

\begin{tabular}{|c|c|}
\hline Wave number $\left(\mathrm{cm}^{-1}\right)$ & Assignments \\
\hline 3408 & $\mathrm{NH}_{2}$ stretching \\
\hline 3086 & $\mathrm{NH}_{3}{ }^{+}$sym.str. and aromatic C-H \\
\hline 2935 & $\mathrm{CH}_{2}$ asym.stretching \\
\hline 2812 & $\mathrm{CH}$ stretching \\
\hline 2599 & $\mathrm{CH}$ stretching \\
\hline 2293 & $\mathrm{C}-\mathrm{O}$ band stretching \\
\hline 2110 & Combination band \\
\hline 1616 & $\mathrm{NH}_{2}$ scissoring \\
\hline 1513 & $\mathrm{NH}_{3}{ }^{+}$torsion \\
\hline 1454 & $\mathrm{CH}_{2}$ Scissoring \\
\hline 1412 & $\mathrm{COO}^{-}$stretching \\
\hline 1360 & $\mathrm{CH}_{3}$ symmetric bending \\
\hline 1302 & $\mathrm{O}-\mathrm{H}$ bending \\
\hline 1234 & $\mathrm{COO}^{-}$sym.stretching \\
\hline 1154 & Phenolic O \\
\hline 1110 & $\mathrm{NH}_{3}+$ rocking \\
\hline 1011 & C-N stretching. \\
\hline 918 & C-C-N sym.stretching \\
\hline 847 & C-C-N sym.stretching \\
\hline 772 & O-C-O deformation \\
\hline 647 & $\mathrm{COO}^{-}$scissoring \\
\hline 539 & $\mathrm{COO}^{-}$rocking \\
\hline
\end{tabular}




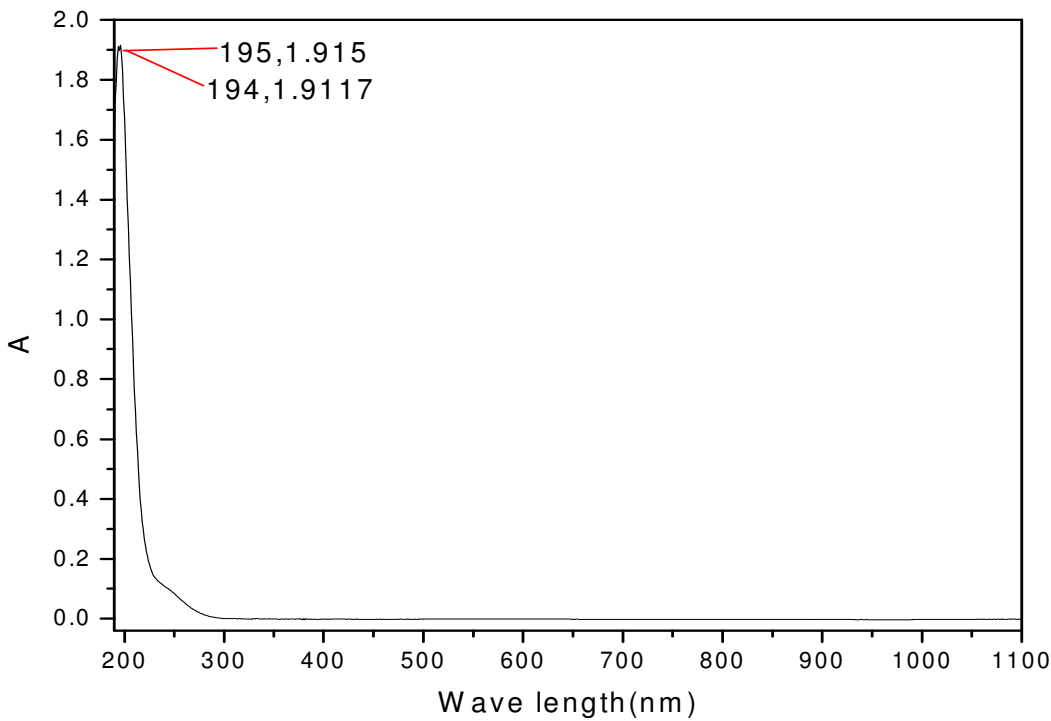

Fig. 6: UV-Visible absorption spectrum for BLATEA crystal

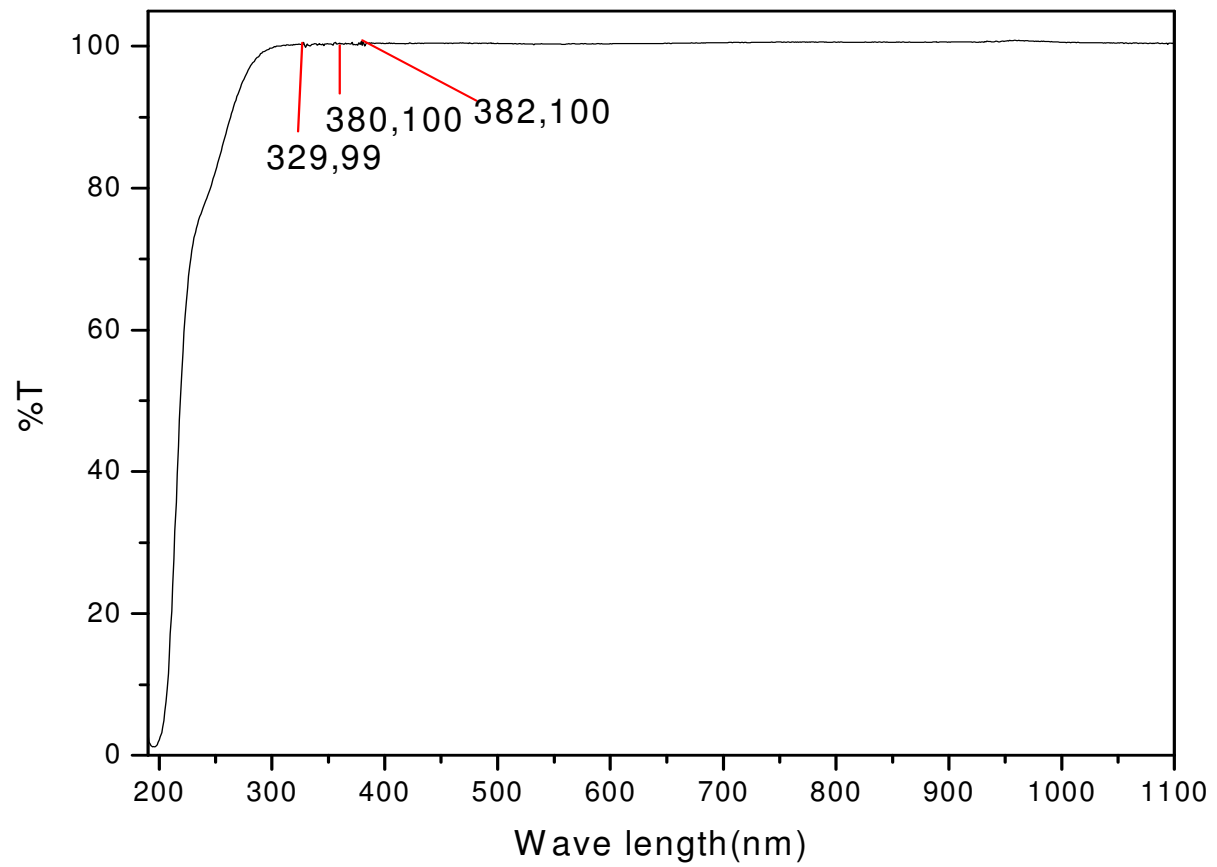

Fig. 7: UV-Visible transmittance spectrum for BLATEA crystal 


\subsection{Mechanical Characterization}

Mechanical strength of a crystal was studied by measuring microhardness and it plays an important role in the fabrication of opto-electronic devices. The hardness of a material is a measure of its resistance to plastic deformation. The permanent deformation can be achieved by indentation, bending, scratching or cutting. In an ideal crystal, the hardness value should be independent of applied load. But in a real crystal, the load dependence is observed. This is due to normal indentation size effect (ISE) [21]. The variation of Vickers hardness number $\left(\mathrm{H}_{v}\right)$ with various loads for BLATEA crystal is shown in Figure 8. It was observed that microhardness number increases with increase in load upto $100 \mathrm{~g}$ and further increase in load causes cracks formation which leads the decrease in hardness value. This may be due to the release of internal stress. Fig. 9 shows the variation of $\log \mathrm{P}$ with $\log \mathrm{d}$ for the crystal of this work. The work hardening coefficient $\mathrm{n}$ was determined from the slope of $\log \mathrm{P}$ versus $\log \mathrm{d}$ plot using least square fit method. The value of $n$ was found to be 2.4. According to theory [22], if $n>1.6$, microhardness value increases with increasing load and decreases with increasing load if $n<$ 1.6. The increase in $\mathrm{H}_{\mathrm{v}}$ for increasing in load observed in the present study is in good agreement with the theoretical predication. Since the work hardening coefficient $\mathrm{n}$ is more than 1.6, the grown BLATEA crystal belongs to the category of soft materials.

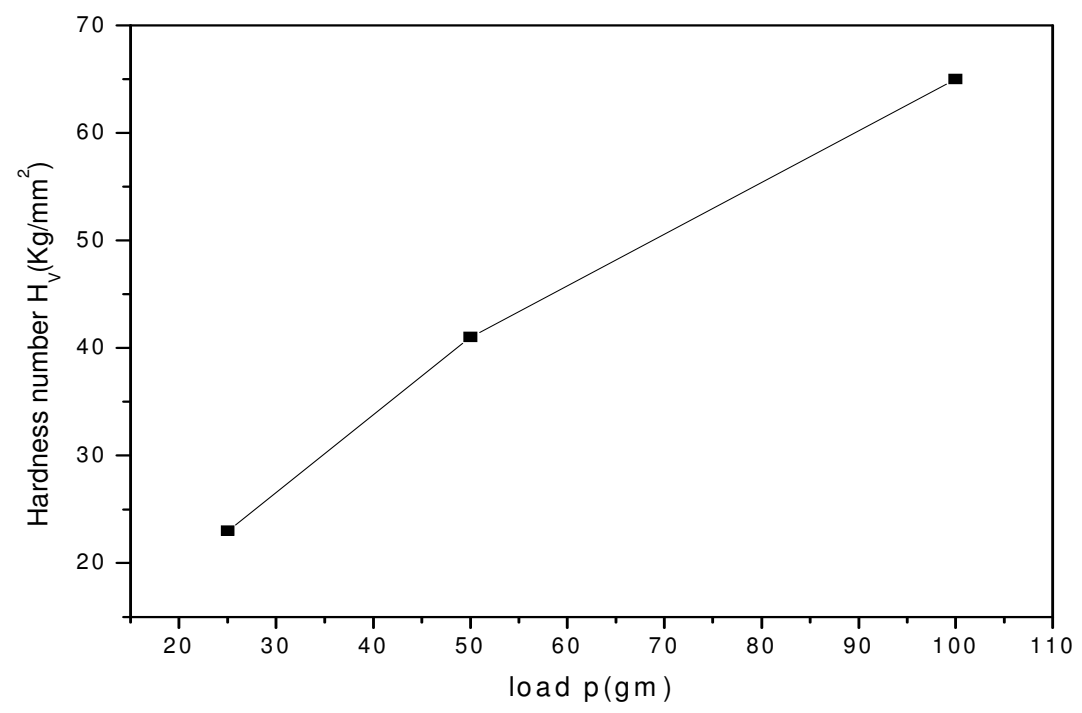

Fig. 8: Variation of Vickers hardness number with load for BLATEA crystal 


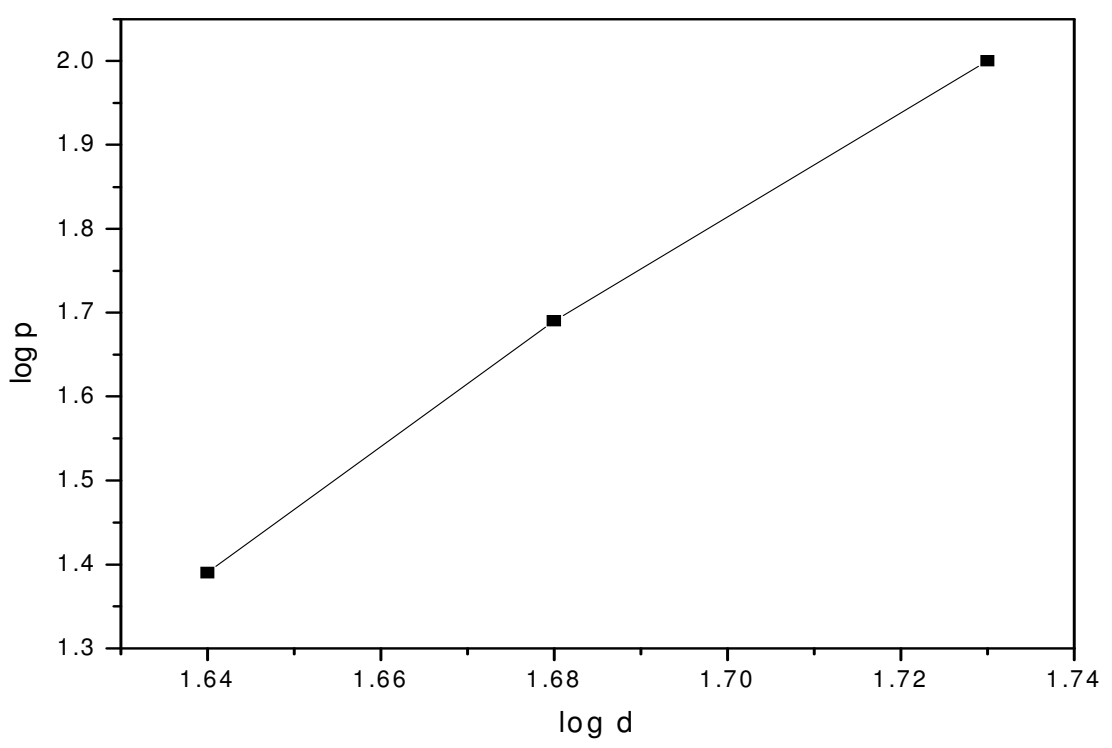

Fig. 9: Variation of $\log \mathrm{P}$ with $\log \mathrm{d}$ for BLATEA crystal

\subsection{Dielectric Characterization}

The plots of frequency dependence of dielectric parameters such as dielectric constant $\left(\varepsilon_{\mathrm{r}}\right)$ and dielectric loss $(\tan \delta)$ of the grown sample of this work at different temperatures like $308 \mathrm{~K}$, $328 \mathrm{~K}, 348 \mathrm{~K}$ and $368 \mathrm{~K}$ are displayed in the Figures 10 and 11. From the results, it is observed that the dielectric parameters decrease with the increase in frequency and increase with increase in temperature. The nature of decrease of $\varepsilon_{\mathrm{r}}$ and $\tan \delta$ with frequency suggests that BLATEA crystal seems to contain dipoles of continuously varying relaxation times. The values of dielectric constant and loss are low at higher frequencies because the dipoles and the charged species of larger relaxation times may not be able to respond to these frequencies. Low value of dielectric loss indicates that the grown crystal is of good quality i.e. the grown crystal is a good quality dielectric material [23]. Variation of the dielectric parameters with temperature is generally attributed to the crystal expansion, the electronic, space charge and ionic polarizations and also attributed to the thermally generated charge carriers and impurity dipoles. As far as polarization is concerned, the increase in dielectric constant with temperature is essentially due to the temperature variation of ionic and space charge polarizations and not due to the temperature variation of orientational polarization [24,25]. AC conductivity $\left(\sigma_{\mathrm{ac}}\right)$ of the sample has been determined using the relation $\sigma_{\mathrm{ac}}=2 \pi \mathrm{f} \varepsilon_{\mathrm{r}} \quad \varepsilon_{\mathrm{o}} \tan \delta$ where $\mathrm{f}$ is the frequency of a.c. supply, $\varepsilon_{\mathrm{r}}$ is the dielectric constant, $\varepsilon_{\mathrm{o}}$ is the permitivity of free space, $\tan \delta$ is the dielectric loss [25]. AC conductivity values are fitted in the equation $\sigma_{\mathrm{ac}}=\sigma_{\mathrm{o}} \exp (-\mathrm{E} / \mathrm{kT})$ where $\sigma_{\mathrm{o}}$ is a constant which depends upon the type of the sample, $\mathrm{E}$ is the activation energy, $\mathrm{k}$ is the Boltzmann's constant and $\mathrm{T}$ is the absolute temperature. A graph is drawn between $\ln \sigma_{\mathrm{ac}}$ and $1 / \mathrm{T}$ which gives a straight line (Fig. 12). The slope of the straight line is equal to $\mathrm{E} / \mathrm{k}$ from 
which the activation energy (E) is calculated to be $0.815 \mathrm{eV}$. The activation energy is the energy required for the charge carriers to take part in the conduction process and the observed high value of activation energy indicates that the sample is an insulating type material.

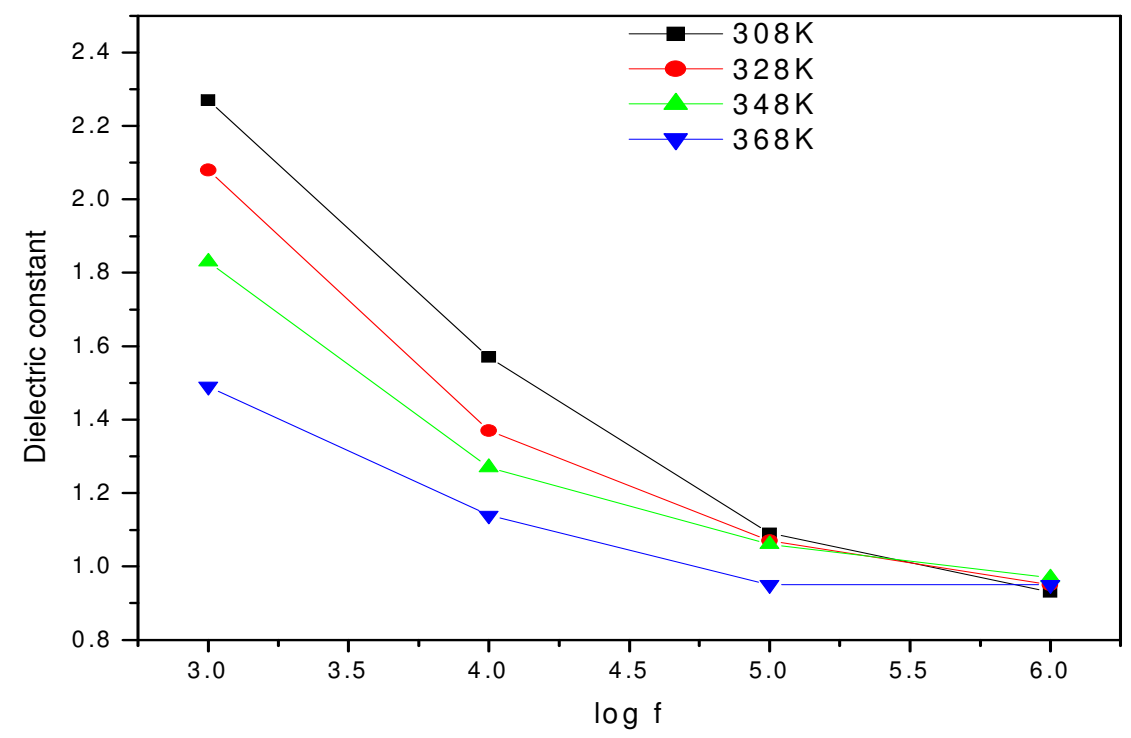

Fig. 10: Frequency dependence of dielectric constant $\left(\varepsilon_{\mathrm{r}}\right)$ for BLATEA crystal at different temperatures

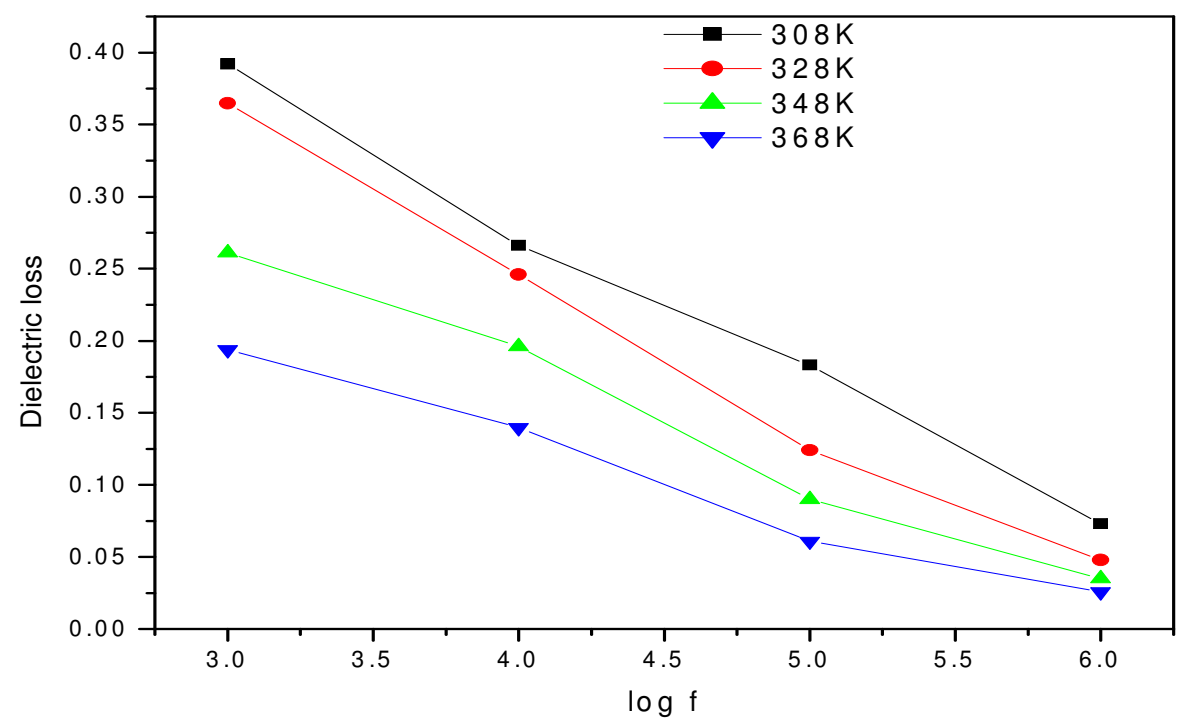

Fig. 11: Frequency dependence of dielectric loss $(\tan \delta)$ for BLATEA crystal at different temperatures 


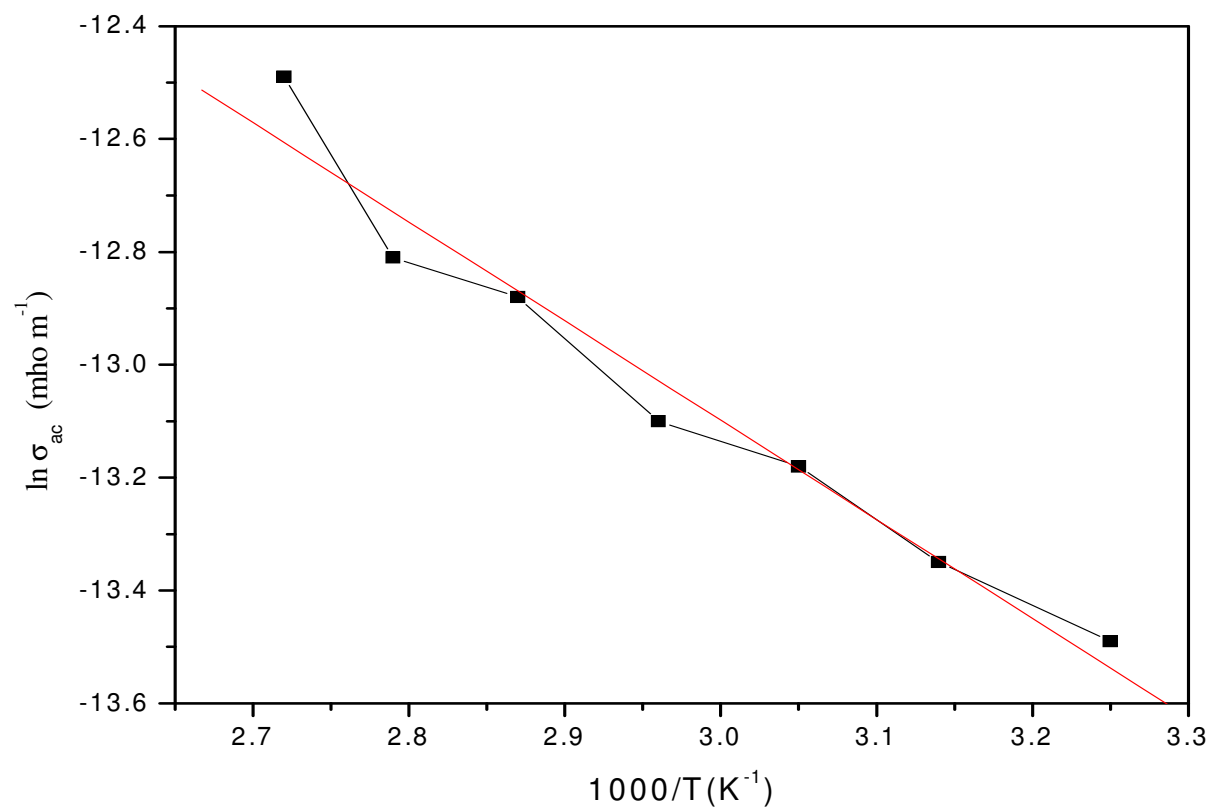

Fig. 12: Plot of $\ln \sigma_{\mathrm{ac}}$ versus 1/T for BLATEA crystal at frequency of $1000 \mathrm{~Hz}$.

\section{CONCLUSIONS}

BLATEA salt was synthesized by solution method by mixing L-alanine and triethanolamine in 2:1 molar ratio and the single crystals of BLATEA have been grown by slow evaporation solution growth technique. The grown crystals were transparent and colourless. The solubility of BLATEA sample was observed to be increasing with increase in temperature. The unit cell parameters for BLATEA crystal have been found out by XRD method and the crystal structure is confirmed to be orthorhombic. The spectroscopic techniques such as FTIR spectral analysis and the optical absorption/transmission studies were carried out to characterize the grown crystals. The NLO efficiency of BLATEA sample is found to be 0.61 times that of KDP. The microhardness study indicates that the crystal belongs to the class of soft materials. The dielectric parameters such as dielectric constant and loss factor of BLATEA were measured at different frequencies and temperatures and the activation energy for the sample for the conduction process was determined to be $0.815 \mathrm{eV}$.

\section{ACKNOWLEDGEMENT}

The supports extended in the research by RRL (Trivandrum), CECRI (Karaikudi), Crecent Engineering college (Chennai), St. Joseph's College (Trichy) and M.K.University (Madurai) are gratefully acknowledged. Also we thank authorities of Management of Aditanar College of Arts 
and Science, Tiruchendur, MDT Hindu College, Tirunelveli and S.T. Hindu College, Nagercoil for the encouragement given to us to carry out the research work.

\section{REFERENCES}

1. J.A.Zerkowski, J.C. Mac Donald, G.M. Whitesides, Chem. Materials 9 (1997)1933.

2. D.S. Chemla, J. Zyss (Eds.), Non linear Optical properties of Organic molecules \& Crystals, Vol 1, Academic Press, Florida, USA, 1986,.

3. S. Manivannan, S. Dhanuskodi, J. Crystal Growth 262 (2004) 473.

4. J. Badan, R. Hierele, A. Perigand, J. Zyss, Am. Chem. Soc. Symp. Ser. 233 in D.J. Williams (Ed.), Am. Chem. Soc.Washington, Dec 1993.

5. http://en.wikipedia.org/wiki/Amino_acids

6. J.D. Bernal, Z. Kristallogr 78 (1931) 363.

7. H.J. Simpson Jr., R.E. Marsh, Acta Cryst. 8 (1966) 550.

8. R. Destro, R.E. Marsh, R. Bianchi, J.Phys.Chem. 92 (1988) 966.

9. V. Bisder-Leib, M.F. Doherty, Cryst. Growth Des. 3 (2003) 221.

10. Thenneti Raghavalu, G. Ramesh Kumar, S. Gokul Raj, V.Mathivanan, R.Mohan, J. Crystal Growth 307 (2007) 112.

11. M. Diem, P.L. Polavarapu, M. Oboodi, L.A. Nafie, J. Am. Chem.Soc. 104(1982) 3329.

12. D. Godzisz, M.H.czysym, M.M.Jesyszym, Spectrochim Acta Part A 59(1)(2003) 681.

13. C. Razzetti, M. Ardoido, L. Zanotti, M. Zha, C. Parorici, Cryst.Res. Technol. 37 (2002) 456.

14. C. Ramachandra Raja, A. Antony Joseph, Materials Letters 63(2009) 2507.

15. A.S.J. Lucia Rose, P. Selvarajan, S. Perumal Rec. Res. Sci.Tech. 2(3) (2010)76.

16. P.Selvarajan, J.Glorium Arulraj, S.Perumal, J. Crystal Growth 311 (2009) 3835.

17. V. Krishnakumar R. Nagalakshmi S. Manohar, L. Kocsis, Spectrochimica Acta Part A 71 (2008) 471.

18. B. Sivasankari and P.Selvarajan J. Exp. Sci. 1(3) (2010) 1.

19. S. K. Kurtz, T.T. Perry, J. Appl. Phys. 39 (1968) 3798.

20. G. Socrates, Infrared Characteristic Group Frequencies, Wiley- Interscience, Chichester, 1980.

21. P.N. Kotru, A.K. Razdan, B.M. Wanklyn, J. Mater. Sci. 24 (1989)793.

22. E.M.Onitsch,Mikroskopie,95(1950)12.

23. K.V. Rao, A. Samakula, J. Appl. Phys. 36 (1965) 2031.

24. P. Selvarajan, B.N. Das, H.B. Gon, K.V. Rao, J. Mater. Sci. 29 (1994) 4061.

25. P. Selvarajan, J. Glorium Arulraj, S. Perumal, Physica B 405 (2010) 738. 